\title{
"Apicum game" - um software educativo sobre mudanças climáticas e seus efeitos nos ambientes marinhos e costeiros
}

\author{
Natalia P. Ghilardi-Lopes ${ }^{1}$, Luciano Silva ${ }^{2}$, Thaís Ribeiro ${ }^{1}$, Juliana C. Braga ${ }^{3}$ \\ ${ }^{1}$ Universidade Federal do ABC, Centro de Ciências Naturais e Humanas, Rua Arcturus \\ 03, CEP 09606-070, Jardim Antares - São Bernardo do Campo - SP - Brasil \\ ${ }^{2}$ Faculdade de Computação e Informática, Universidade Presbiteriana Mackenzie, Rua \\ da Consolação, 930, CEP 01302-907 São Paulo, Brasil \\ ${ }^{3}$ Universidade Federal do ABC, Centro de Matemática, Computação e Cognição, \\ Avenida dos Estados, 5001, CEP 09210-580, Santo André, Brasil \\ natalia.lopes@ufabc.edu.br; lucianosilva@mackenzie.br; \\ tha.sribeiro@gmail.com; juliana.braga@ufabc.edu.br
}

\begin{abstract}
The educational game "Apicum game" is targeted for 12 to 14 years old children and works with global environmental change and their effects on coastal and marine ecosystems. The game's setting is a fictional coastal town called Apicum and the main character will have the task of investigating the causes of weather phenomena in the city that are affecting organisms in the coral reef. Throughout the game, the character earns points of "Economy", "Environment" and "Society" and at the end of the game his/her "sustainability index" is calculated. The prototype of the game, already tested by 22 children, is available HERE.
\end{abstract}

Resumo. O jogo educativo "Apicum game” é voltado para crianças dos 12 aos 14 anos e trabalha as mudanças climáticas globais e seus efeitos nos ambientes marinhos e costeiros. O cenário do jogo é uma cidade fictícia costeira chamada Apicum e o personagem principal terá a tarefa de investigar as causas dos fenômenos climáticos na cidade que estão afetando os organismos no recife de coral. Ao longo do jogo, o personagem ganha pontos de "Economia", "Ambiente" e "Sociedade" e ao final do jogo é calculado o seu "Índice de sustentabilidade”. O protótipo do jogo, já testado por 22 crianças, está disponível $\underline{A Q U I}$.

\section{Cenário de Uso}

O conceito científico de Mudança Climática é difícil para a maioria da população, que tende a percebê-lo como um problema abstrato no tempo e espaço [Tamaio 2010].

É importante, portanto, promover um ensino, em todos os espaços de aprendizagem, baseado no aprofundamento científico sobre o tema [Jacobi et al. 2011], imprimindo maior transversalidade ao mesmo, pois as Mudanças do Clima (e suas causas) também possuem interfaces indissociáveis com as esferas social, cultural, psíquica e econômica [Tamaio 2010], além da ambiental. Dentro deste contexto, os objetos de aprendizagem (OAs) educativos, de livre acesso na internet ou para uso em 
sala de aula, podem configurar-se como ferramenta poderosa neste processo de educação científica de forma adaptada ao público geral, possibilitando a apreensão e compreensão das informações, e, finalmente, a extensão de tudo isso para a mudança de comportamentos e realização de ações com fins à melhoria da qualidade socioambiental.

Diante desse cenário, este projeto desenvolveu um jogo que visa promover o ensino, principalmente para estudantes do ensino fundamental e médio, de conteúdos (procedimentais, atitudinais e conceituais) relacionados às mudanças climáticas globais e seus efeitos sobre os ecossistemas marinhos e costeiros.

\section{Desenvolvimento}

Antes de se partir para o design tradicional de jogos, sentiu-se a necessidade de incluir elementos pedagógicos desde o início de seu desenvolvimento. Para tanto, o primeiro passo foi preencher um artefato de contextualização pedagógica do jogo sugerido pela metodologia de desenvolvimento de OAs, denominada INTERA [Braga et al. 2015] (Tabela 01).

Tabela 01. Contextualização: artefato do "Apicum Game”.

Descrição

\section{Tipo de OA}

Objetivos Pedagógicos

Área de conhecimento

Disciplina principal

Breve Descrição

Público-alvo

Conhecimentos prévios necessários

Grau de acessibilidade

Conhecimento tecnológico necessário

Principal problema que motivou a criação do OA

Solução esperada
Software (jogo).

Possibilitar a estudantes refletir sobre suas atitudes e valores relativos à sustentabilidade.

Interdisciplinar (biologia, ecologia, política, economia, física, química).

\section{Ecologia.}

O jogo trabalha causas e consequências das mudanças climáticas, com ênfase em ambientes marinhos e costeiros. Os três pilares da sustentabilidade são abordados, através da realização de tarefas e desafios pelo jogador.

Estudantes de ensino fundamental e médio

Conhecimento básico em ecologia, embora todos os conceitos sejam explicados no jogo.

O jogo não possibilita a participação de crianças com deficiência visual ou auditiva.

Os estudantes devem conhecer regras básicas de uso de um computador.

Há poucos OAs que lidam com o tema das mudanças climáticas. Poucas pessoas conhecem os ambientes marinhos e costeiros e as relações entre estes e suas atividades diárias.

Que o jogo possa ajudar estudantes a entender sobre ecossistemas marinhos e costeiros e mudanças climáticas. Ainda, quais ações podem ajudar a minimizar o problema. 
Após a elaboração desse artefato, iniciou-se o desenvolvimento do jogo baseado em metodologias tradicionais de design de games. A equipe do projeto foi inicialmente formada por uma professora doutora em ciências biológicas (coordenadora do projeto e conteudista) e dois professores doutores em ciência da computação (um exercendo o papel de arquiteto e consultor técnico especialista e o outro atuando como engenheiro de software). A princípio, foi definido o backlog inicial do projeto, no qual foram definidas as atividades previstas, períodos de execução e responsáveis por cada uma das mesmas. Os alunos selecionados para desempenharem a função de desenvolvedores do jogo realizaram a leitura de capítulo de livro sobre mudanças climáticas e os seus efeitos nos ambientes marinhos e costeiros [Berchez et al. 2008]. Também foi feita visita ao Projeto Trilha Subaquática no Parque Estadual da Ilha Anchieta (Ubatuba, SP) para que todos se familiarizassem e se sensibilizassem para a temática do jogo. Ainda neste período inicial, os alunos se familiarizaram com o Game Maker, software escolhido para o desenvolvimento do jogo [Habgood and Overmars 2006].

Para que o grupo interagisse foi criado o grupo no Facebook "Projeto Jogos Marinhos" [Silva et al. 2013]. Adotou-se a metodologia SCRUM [Keith 2010] para o gerenciamento das tarefas. A equipe elaborou o Game Design Document (GDD) e o Level Design Document (LDD). O jogo foi pensado como uma linha em que a realização de algumas ações desbloqueia outras possíveis interações [Gonçalves 2004].

\section{Apresentação do software}

O jogo ocorre em uma cidade costeira fictícia denominada Apicum, a qual tem apresentado algumas circunstâncias estranhas, como altas intensidades de chuva e altas temperaturas. De acordo com a professora do personagem principal (o jogador), os ecossistemas costeiros locais também estão sofrendo com estas anomalias climáticas. Então, o personagem principal terá a tarefa de investigar as causas destes fenômenos climáticos na cidade e no recife de coral próximo à costa de Apicum. Para isso, passará por nove fases, nas quais ganhará pontos de "Ambiente", "Sociedade" ou "Economia", os três pilares da sustentabilidade.

Para instalação do jogo, o usuário deve aceitar os termos de uso do software Game Maker. O software é compatível com o sistema operacional Windows.

Antes do início da estória propriamente dita, o jogador poderá personalizar seu personagem, escolhendo o sexo, cor de cabelo e roupas (Figura 01a).

a)

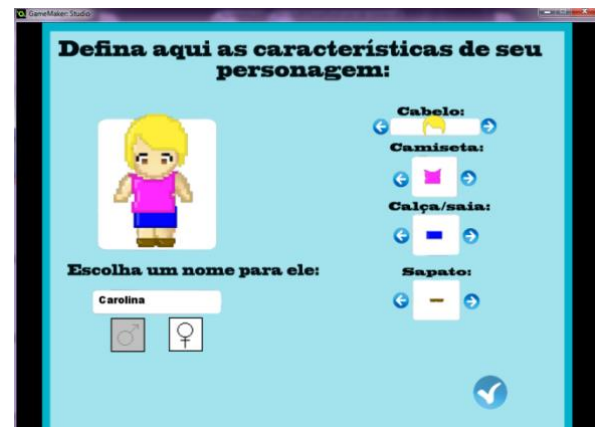

b)

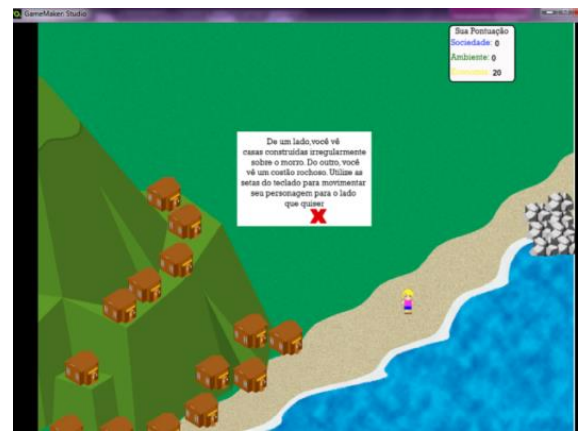

Figura 01. a) Tela inicial de personalização do personagem principal. b)Tela introdutória, dando duas opções de caminho para o personagem principal. Notar a tabela de pontuação no canto superior direito da tela. 
CBIE-LACLO 2015

Anais dos Workshops do IV Congresso Brasileiro de Informática na Educação (CBIE 2015)

\section{Nível introdutório}

Na introdução (Figura 01b), o personagem estará na praia e terá duas opções:

1) ir para a esquerda (Figura 02a), onde verá algumas construções ilegais danificadas por uma tempestade extrema, conversará com um morador local e poderá ajudar algumas pessoas a ir para um abrigo (por meio de um minigame - Figura 02b);
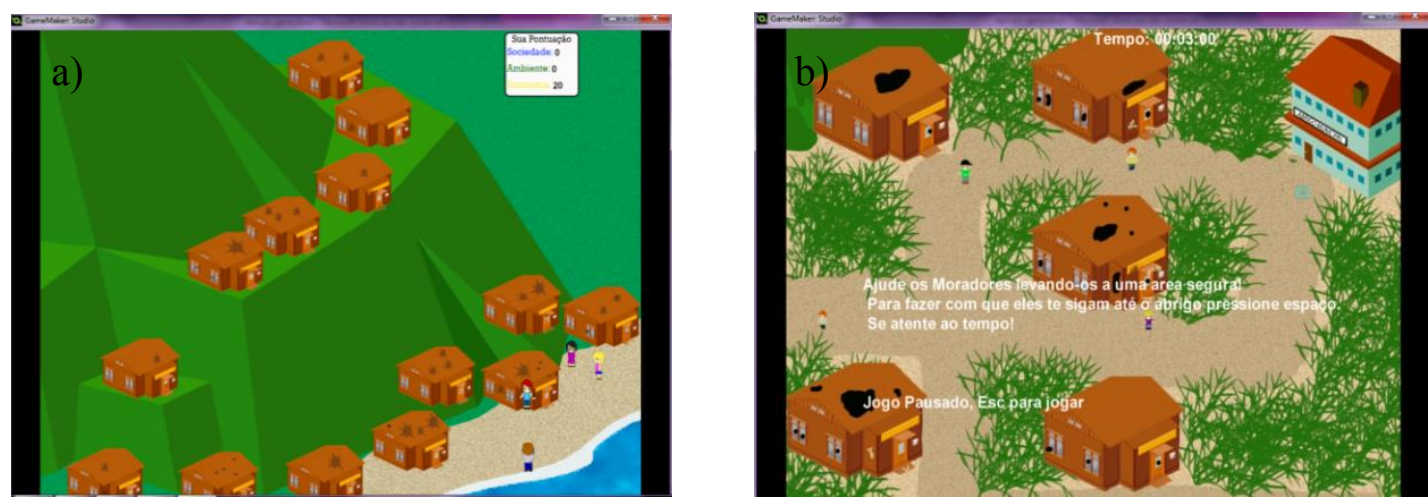

Figura 02. a) Caminho à esquerda da tela introdutória; b) Minigame onde o jogador ajudará os moradores afetados pela tempestade a irem para um abrigo, ganhando pontos de "Sociedade".

2) ir para a direita (Figura 03a), onde conhecerá ecólogos marinhos que trabalham em um costão rochoso e o jogador terá a oportunidade de ajudar na investigação dos cientistas (Figura 03b). Esta interação tem a intenção de desmistificar a visão do cientista como "uma pessoa que usa um jaleco e permanece o tempo todo dentro de um laboratório", muito comum entre os alunos da educação básica.
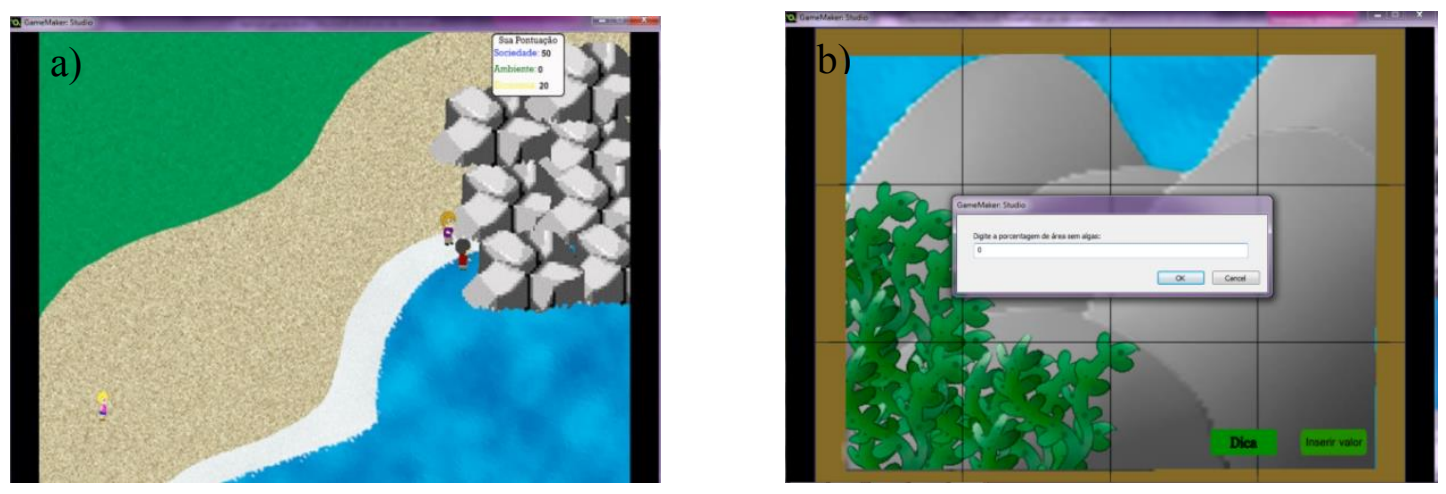

Figura 03. a) Caminho à direita no nível introdutório, com ecólogos estudando os costões rochosos; b) Minigame onde o jogador deve calcular a área de rocha sem cobertura de algas, ganhando pontos de "Ambiente".

Após estas duas possibilidades de interação, o personagem vai para sua casa, onde conhecerá o personagem Caobimpará, que incentivará o personagem principal a saber mais sobre o que está acontecendo na cidade.

\section{Nível Biblioteca}

Ao longo de todos os níveis haverá um nível desbloqueado, que é o nível biblioteca (Figura 4a), em que o leitor será capaz de se informar sobre alguns assuntos relacionados ao jogo. 
CBIE-LACLO 2015

Anais dos Workshops do IV Congresso Brasileiro de Informática na Educação (CBIE 2015)

\section{Nível Escola - parte 01}

Neste nível, a professora fala sobre mudanças climáticas globais faz algumas perguntas. No final, pede aos alunos que meçam suas emissões de gases de efeito estufa.

Nível Casa do personagem principal (Figura 04b)

Neste nível, o jogador irá calcular suas emissões de gases de efeito estufa. Depois disso, o jogador terá que voltar para a escola, onde irá comparar o resultado com a média das emissões brasileiras (que é aprox. 1,8 toneladas per capita por ano).

a)

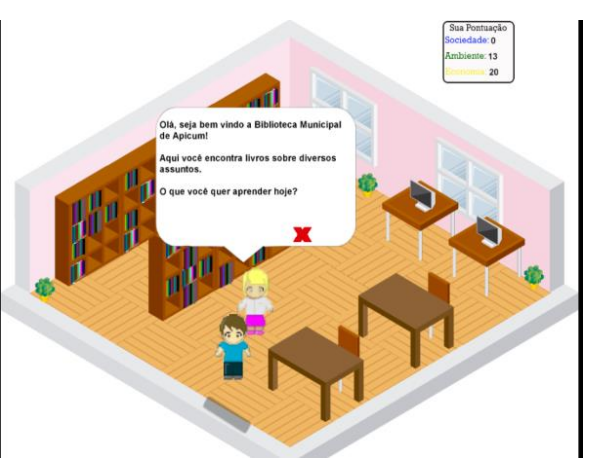

b)

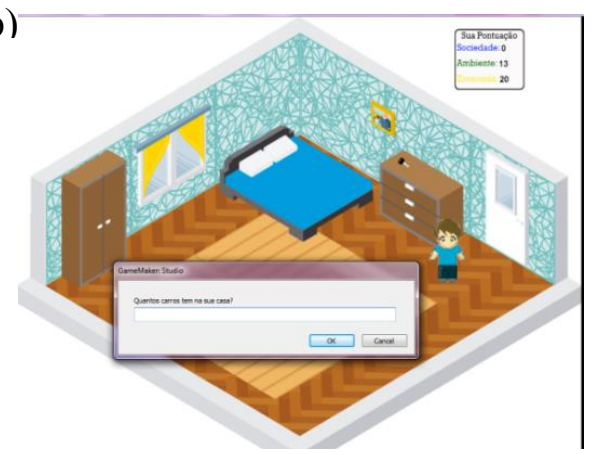

Figura 04. a) Nível Biblioteca; b) Um dos cômodos da casa do personagem, onde será realizado o cálculo das emissões de gases do efeito estufa.

\section{Nível Escola - parte 02}

Nesta parte, a professora falará sobre as emissões de gases de efeito estufa e suas consequências para o meio ambiente. Além disso, o jogador aprenderá sobre os ecossistemas marinhos e costeiros (minigame - Figura 05a). No final, a professora pede aos alunos uma pesquisa e o nível "Recife de Coral" será desbloqueado (Figura 05b).

a)

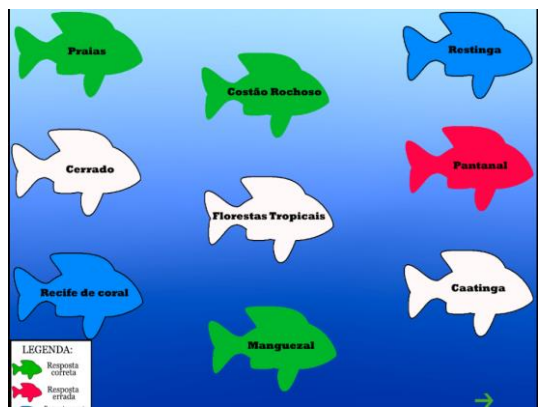

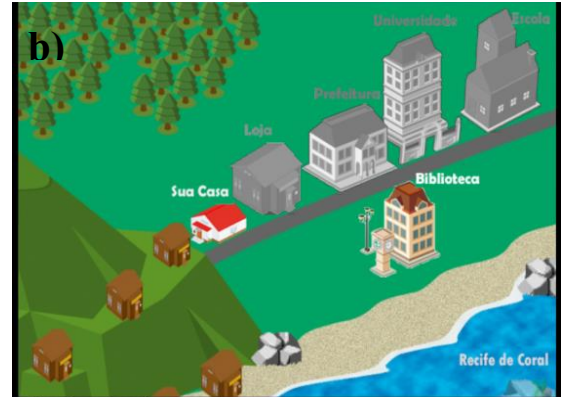

Figura 05. a) Minigame sobre os ecossistemas marinhos e costeiros; b) Mapa do jogo, com as fases bloqueadas apresentadas na cor cinza.

\section{Nível Recife coral - parte 01 (Figura 06)}

Neste nível, o jogador conversará com pescadores e pedirá uma carona até o recife de coral. Os pescadores vão explicar que é necessário saber mergulhar e ter equipamentos de mergulho. Para ganhar dinheiro, o jogador poderá ajudar os pescadores com o seu trabalho. No final deste nível, o nível "loja" será desbloqueado.

\section{Nível Loja e Recife de Coral - parte 02 (Figura 07)}

$\mathrm{Na}$ loja, o jogador será capaz de comprar equipamentos de mergulho. Ao retornar para o recife de coral, o jogador será capaz de mergulhar. Durante o mergulho, 
encontrará Caobimpará novamente e eles vão falar sobre o branqueamento de corais. $\mathrm{O}$ jogador será capaz de tomar algumas medidas ambientais, mas precisará dos equipamentos que pode conseguir na universidade (se o jogador decidir ir para o nível de "Universidade" em primeiro lugar, ele / ela pode já ter os equipamentos).

a)

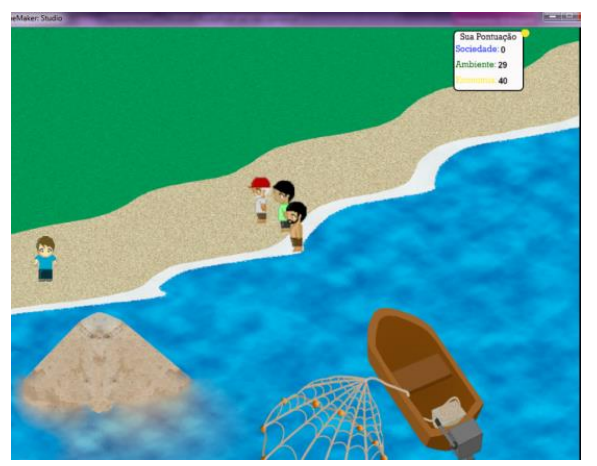

b)

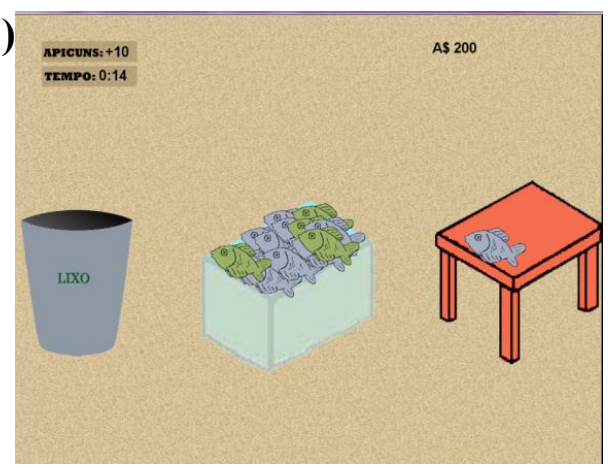

Figura 06. a) Fase Recife de Coral, onde o jogador conversa com pescadores; b) Minigame de separação de peixes, onde o jogador ganha pontos de "economia" que o ajudarão a comprar os equipamentos de mergulho.

a)

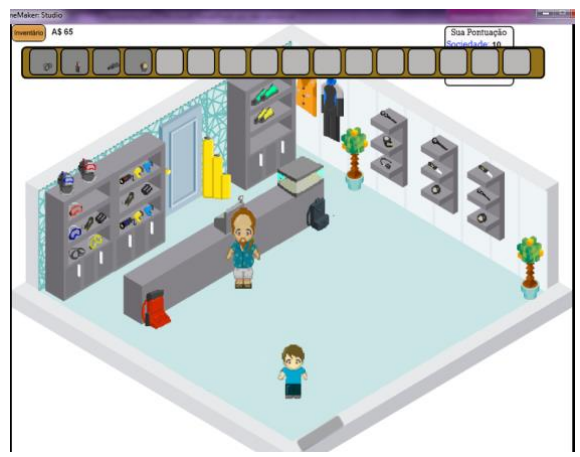

b)

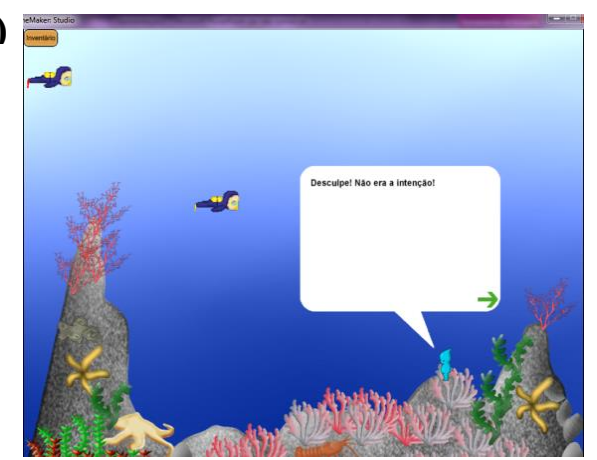

Figura 07. a) Fase loja, onde será possível comprar os equipamentos de mergulho e adicioná-los ao inventário (parte superior da tela); b) Recife de coral, onde o personagem encontra Caobimpará.

Nível Universidade (Figura 08a)

Neste nível, o jogador vai falar com um cientista, formular hipóteses e será direcionado para obter alguns equipamentos no nível "laboratório".

Nível Laboratório (Figura 08b)

Lá, o jogador terá que encontrar um termômetro, pHmetro, turbidímetro, oxímetro, medidor de nutrientes e uma unidade de amostragem. Com os equipamentos em mãos, o jogador será capaz de tomar as medidas ambientais no recife de coral.

Após realizar as medidas, o jogador deve voltar para a universidade e falar com o cientista de novo. Ao falar com o cientista, o jogador vai entender que as questões ambientais são relacionadas também à política e o nível "Prefeitura" é desbloqueado.

Nível Prefeitura (Figura 09a)

$\mathrm{Na}$ prefeitura, o jogador será capaz de simular o voto em candidatos com diferentes proposições sobre "Ambiente", "Sociedade" e "Economia", e fazendo isso, o jogador vai ganhar pontos nessas três dimensões. O objetivo é mostrar ao jogador que há 


\section{CBIE-LACLO 2015}

Anais dos Workshops do IV Congresso Brasileiro de Informática na Educação (CBIE 2015)

uma relação entre as nossas escolhas e aquilo que acontece com o meio ambiente, a sociedade e a economia e que a partir do nosso voto podemos definir nosso futuro.

Nível escola - parte 03 (Figura 09b)

Depois disso, o jogador deve voltar para a escola, a fim de apresentar seus resultados para a professora (todos os pontos dos níveis se resumem aqui). Será calculado o seu índice de sustentabilidade e, no final, o jogador que ganhar mais pontos e for o mais equilibrado nestas três dimensões será o mais bem sucedido.

a)

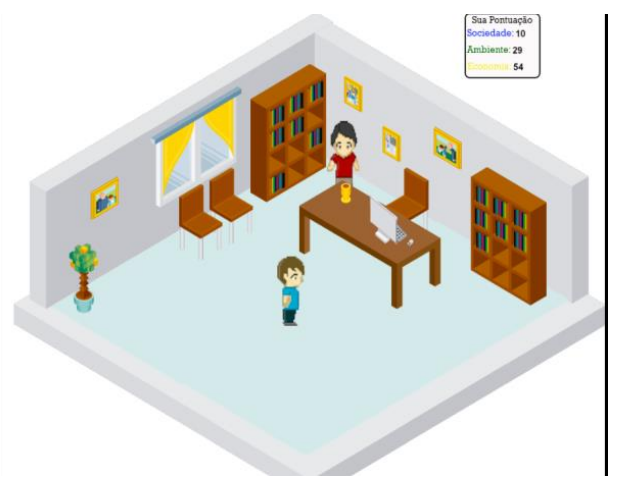

b)

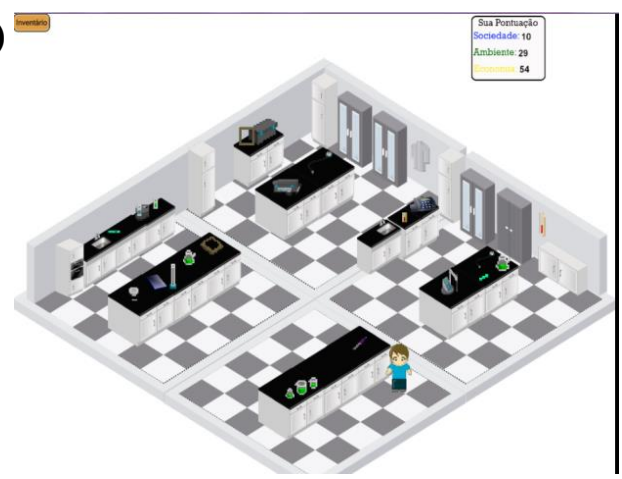

Figura 08. a) Fase Universidade; b) Fase laboratório.

a)

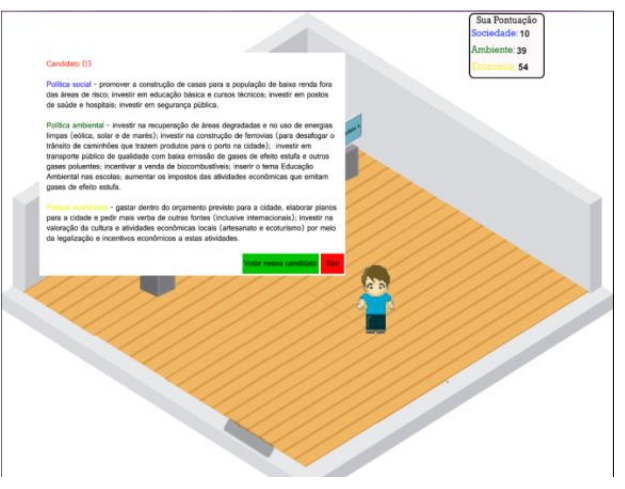

b)

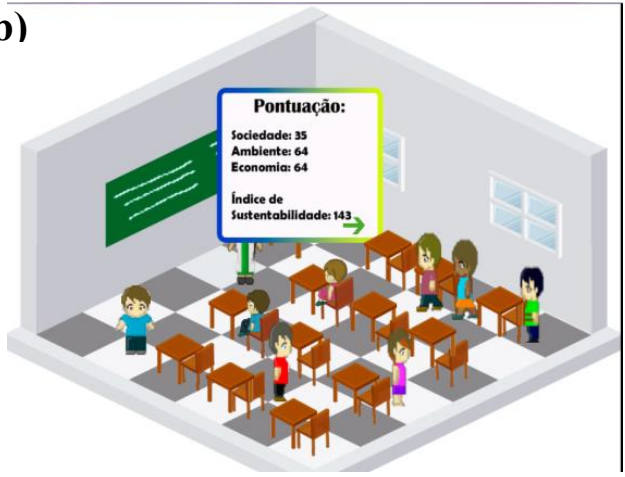

Figura 09. a) Fase prefeitura; b) Fase final, onde é calculado 0 índice de sustentabilidade do jogador.

\section{Considerações finais}

Gee [2003] argumenta que jogos instrucionais deveriam incluir habilidades, conhecimentos e valores que permitam ao jogador experimentar como membros de uma profissão específica pensam, comportam-se e resolvem problemas (profissionalismo autêntico). Assim, quando o jogador conversa com ecólogos marinhos e vai até a universidade conversar com o professor, este tipo de interação e experiência é possibilitado. Um dos objetivos do jogo é ensinar as etapas do método científico (observação, formulação de hipótese, experimentação, descrição e discussão de resultados e conclusão) de forma intuitiva. A ideia é que o professor use o jogo para propor questões problematizadoras aos estudantes, com o objetivo de desenvolver a argumentação e discussão de soluções [Andrade and Campos 2009]. Assim, vemos o jogo como uma oportunidade para ensinar sobre o método científico e seu uso para a investigação de problemas ambientais, de acordo com os objetivos da alfabetização científica [Sasseron and Carvalho 2008], os quais podem ser incluídos em três eixos 


\section{CBIE-LACLO 2015}

Anais dos Workshops do IV Congresso Brasileiro de Informática na Educação (CBIE 2015)

estruturantes: (1) compreensão básica de termos, conhecimento e conceitos científicos fundamentais; (2) compreensão da natureza da ciência e os fatores éticos e políticos que acompanham sua prática e (3) entendimento das relações entre ciência, tecnologia sociedade e ambiente.

\section{Referências}

Andrade, M.A.B.S. and Campos, L.M.L. (2009) "A resolução de problemas no ensino de ciências e biologia." In Introdução à Didática da Biologia, edited by A. M. A. Caldeira and E. S. N. N. Araujo, pp. 220-32. São Paulo: Escrituras.

Berchez, F.A.S., Oliveira Filho, E.C., Amâncio, C.E., and Ghilardi, N.P. (2008) "Possíveis impactos das mudanças climátcias globais nas comunidades de organismos marinhos bentônicos da costa brasileira." In Biologia \& Mudanças Climáticas no Brasil, edited by M. Buckeridge, pp. 167-80. São Carlos: RiMa Editora.

Braga, J.C., Pimentel, E., and Dotta, S. (2015) "Processos e Metodologias para o Desenvolvimento de Objetos de Aprendizagem." In Objetos de Aprendizagem, edited by J. C. Braga, pp. 23-56. Santo André: Editora da UFABC.

Chassot, A. (2003) "Alfabetização científica: uma possibilidade para a inclusão social.” Revista Brasileira de Educação 22: 89-100.

Gonçalves, W.J. (2004) “Turismo (In)sustentável em Morro de São Paulo, Bahia. Existe turismo sustentável em Morro de São Paulo?" Centro de Excelência em Turismo. pp. 67. Brasília: Universidade de Brasília.

Habgood, J. and Overmars, M. (2006) The Game Maker's Apprentice: Game Development for Beginners. New York: Apress.

Jacobi, P.R., Guerra, A.F.S., Sulaiman, S.N., and Nepomuceno, T. (2011) "Mudanças climáticas globais: a resposta da educação." Revista Brasileira de Educação 16(46): 135-48.

Keith, C. (2010) Agile Game Development with SCRUM. New York: Addison-Wesley Professional.

Sasseron, L.H. and Carvalho, A.M.P.d. (2008) "Almejando a alfabetização científica no ensino fundamental: a proposição e a procura de indicadores do processo." Investigações em Ensino de Ciências 13(3): 333-52.

Silva, L., Braga, J.C., Ghilardi-Lopes, N.P., Pinhata, E., Simões, E., Ribeiro, T., Ribeiro, E.Q., and Shinohara, B. (Year) "Educational game on global environmental changes: Collaborative design using a social network." In Proceedings of SBGames 2013, edited by, pp. 520-23. São Paulo: Sociedade Brasileira de Computação.

Tamaio, I. (2010) "Uma proposta de política pública: Parâmetros e Diretrizes para a Educação Ambiental no contexto das Mudanças Climáticas causadas pela ação humana ". MMA, pp. 105. Brasília: Ministério do Meio Ambiente. 